\title{
Inhibitory Effects of Collagen Coated Coffee Bean Intake on Skin Aging
}

\author{
In-Ah Lee', Mi-Ae Ha², and Yong-Wook Shin ${ }^{2,3 *}$ \\ 'Department of Chemistry, College of Natural Science, Kunsan National University, Gunsan 54150, Korea \\ ${ }^{2}$ Department of Agronomy \& Medicinal Plant Resources, Gyeongnam National University of Science and Technology, Jinju 52725, \\ Korea \\ ${ }^{3}$ International Garden Institute, Gyeongnam National University of Science and Technology, Jinju 52725, Korea
}

\begin{abstract}
To evaluate the protective effect of collagen peptide-coated coffee extract on skin aging, cell viability was measured with a MTT assay using cultured CCD-986sk fibroblasts, and its effect on wrinkles in the skin of hairless mice induced by UVB-irradiation was examined. In addition, its effect on procollagen synthesis and anti-oxidative, and its inhibitory activity against collagenase, elastase, tyrosinase and MMP-1 were analysed. After the 30-minute topical treatment, the animals were exposed to UVB irradiation $\left(60-100 \mathrm{~mJ} / \mathrm{cm}^{2}\right)$ for 4 weeks and its intensity increased during the period. Under the experimental conditions set in this study, the skin thickness of hairless mice significantly decreased (11.8-21.3\%) compared to the control group. Based on these results, the prolonged oral intake of a collagen peptide mixture with coffee is expected to significantly increase the synthesis of procollagen in dermal fibroblasts, thereby contributing to the alleviation of wrinkling and lowered elasticity due to structural damage to the dermal layer caused by UV. The oral intake of collagen-coated coffee contributes to increasing collagen biosynthesis in a dose-dependent manner and alleviates the symptoms of thickened keratin caused by UV irradiation. However, it did not inhibit the enzymes involved in skin aging, whitening, wrinkle improvement, and antioxidation. Based on the these results, it can be concluded that the intake of collagen peptide-coated coffee extract can be utilized as an alternative material for the prevention or treatment of diseases associated with photoaging.
\end{abstract}

Keywords: coffee bean, collagen peptide, collagen synthesis, photo-aging

\section{Introduction}

In terms of coffee consumption, South Korea, as a single country, was ranked sixth in the world in 2017 (Hong, 2018), showing the world's highest consumption of coffee except those that produce coffee. Coffee contains many bioactive chemical substances that affect the body in many different ways such as caffeine, chlorogenic acid, and diterpenes (Santos and Lima, 2016). In particular, antioxidants such as chlorogenic acid (Moreira et al., 2005), caffeine (Vignoli et al., 2011) and melanoidin (Delgado-Andrade and Morales, 2005) were also reported, and the intake of these antioxidants contained in coffee prevents aging, cardiovascular diseases and various metabolic diseases caused by reactive oxygen species in the

This study was supported by the Gyeongnam National University of Science and Technology in 2017.

Received: January 31, 2019 Revised: February 1, 2019, Accepted: February 2, 2019

First author: In-Ah Lee, E-mail: leeinah@kunsan.ac.kr, ORCID: 0000-0003-1092-471X

*Corresponding author: Yong-Wook Shin, E-mail: ywsynn@gntech.ac.kr, ORCID: 0000-0002-4983-0107 
body (Benzie, 2000). Chlorogenic acid is one of the caffeoylquinic acids mainly induced by esterification between quinic acids and phenolic acids such as caffeic acid, ferulic acid and p-coumaric acid, and is found in various higher plants (Bicchi et al., 1995). This substance is a type of polyphenols contained in coffee beans, known to be involved in the color and bitter taste of coffee (Vignoli et al., 2011). Polyphenols are one of the most abundant compounds in people's diet, and, chlorogenic acid, in particular, is a secondary phenolic metabolite produced in certain plant species and have several biological characteristics such as antibacterial, antioxidant and anticarcinogenic reactions (Meng et al., 2013). Recent studies reported that the intake of coffee is associated with a decrease in the risk of type 2 diabetes, and those who drink a moderate amount of coffee were found to have a lower risk of diabetes than those who do not drink coffee. Coffee intake is known to be involved in the frequency of impaired glucose tolerance, glycosemia and reduced insulin sensitivity, which was reported to be caused by chlorogenic acid and other substances in coffee (Bidel and Tuomilehto, 2012). It was also reported that those who drank 3 to 4 cups of coffee a day have a lower risk of type 2 diabetes, which can be attributed to the existence of chlorogenic acid and caffeine that are increased after roasting coffee beans (Santos and Lima, 2016). Meanwhile, the relation between coffee roasting and the amount of antioxidants is still open to dispute. Some studies argued that green beans have more antioxidant effects due to the absence of the breakdown of chlorogenic acid, and it was also reported that green beans before roasting are effective in relieving pain (Lee et al., 2018). Another study reported that coffee roasting breaks down chlorogenic acid and thus reduces the antioxidant effect of coffee, but that heating generates melanoidins and thus does not have a significant impact on antioxidation (Vignoli et al., 2011). The study also reported that the antioxidant effect of light roasting is higher than that of strong roasting.

The antioxidant reaction of different coffee varieties was compared, and it was reported that the antioxidant activity of C. canephora was higher than that of Coffea arabica preferred by Koreans (Moreira et al., 2005).

As the domestic consumption of coffee increases, people's interest in increasing the functionality of coffee through processing such as blending coffee and medicinal plants or fermenting coffee has also increased, and many studies have been conducted focusing on this such as a study on a functional beverage that used coffee beans and a medicinal plant extract to increase antibacterial and antioxidant functions (Kim et al., 2016); a study on the comparison of antioxidant activity depending on the mixed ratio of coffee powder and red ginseng powder (Choi et al., 2012); a study on functional materials produced by fermenting mushroom and Monascus ruber in the solid state to increase the functionality of brewed coffee for preventing chronic diseases (Shin et al., 2013); and a study on the effects of the hot-water extract of coffee beans fermented with Monascus ruber in the solid state on the inhibition of fat accumulation (Lim et al., 2014). The yeast fermentation of green coffee beans significantly increased antioxidant activity, and thus effectively enhanced the functionality of coffee. The consumer acceptability of fermented coffee beans, however, was lower than the control group, but increased in some fermented coffee types, which indicated that consumers' preference can increase unless the yeast fermentation of coffee beans has negative smells and tastes (Kwak et al., 2018).

As such, various attempts have been made to maximize the functionality and preference of coffee, but there are only few studies on technology for coating the surface of coffee beans with drugs and the functionality of coated coffee beans. In particular, there is almost no study on the functionality of coffee beans coated with collagen, and thus it seems to be meaningful to research the effect of coffee beans coated within the concentration level that does not spoil the natural aroma and taste of coffee and to examine skin enzyme inhibition associated with skin aging in skin cells, providing basic research results. Against this backdrop, this study aimed to examine the effect of the extract from collagen-coated coffee beans on the inhibition of skin aging from the aspect of the reduction of wrinkles and collagen synthesis. 


\section{Research Methods}

\section{Sample preparation}

Collagen-coated coffee beans were produced by coating coffee beans (98.7\%), purchased from 'Foodreams,' with fish collagen-peptide mixed powder (1.3\%). Two types of coffee beans were coated with collagen peptide as follows: Collafee bean (200 $\mathrm{g}$ of coffee beans coated with 2,000 $\mathrm{mg}$ of collagen (1,200 Da or lower)) and Collafee bean presso (200 $\mathrm{g}$ of coffee beans coated with 4,000 mg of collagen (1,000 Da or lower)). They were extracted in hot water and were freeze-dried.

\section{Laboratory animals}

Six-week-old female nude mice (Skh-1) were purchased from Orient Bio Inc. (Seongnam, Gyeonggi), and were divided into 4 groups after the acclimation period. The nurturing environment for the animals used in this study was as follows: temperature $\left(24 \pm 2^{\circ} \mathrm{C}\right)$, humidity $(55 \pm 10 \%)$ and light-dark cycle (12 hours). The mice were fed on the mouse feed purchased from Feed Lab Korea (Guri, Korea), and they were treated according to the "Guide for the Care and Use of Laboratory Animals."

\section{Measurement of electron donating activity (DPPH)}

The reducing power of each sample was measured as the electron donating effect of 1,1-diphenyl-2-picryl hydrazyl (DPPH). That is, $0.5 \mathrm{ml}$ of $0.4 \mathrm{mM}$ DPPH was added to $1 \mathrm{ml}$ of each extract sample produced by different concentrations, and each sample was vortex-mixed for 10 seconds and was reacted at $37^{\circ} \mathrm{C}$ for 30 minutes. After that, the absorbance of the reacted solution was measured at $517 \mathrm{~nm}$ using a microplate reader.

\section{Cell culture}

CCD-986sk (Human fibroblast) cells purchased from ATCC were cultured in a $5 \% \mathrm{CO}_{2}$ culture incubator at $37^{\circ} \mathrm{C}$ using a culture medium prepared by adding a $10 \%$ heat-inactivated fetal bovine serum (FBS; GibcoBRL) and $1 \%$ gentamicin to Dulbecco's modified Eagle medium (DMEM).

\section{Measurement of cell viability}

Cells $\left(8 \times 10^{4}\right.$ cells $\left./ \mathrm{ml}\right)$ were divided into a 96-well plate, and were stabilized and treated with the extract of different concentrations. After culturing cells for 24 hours, the culture medium was removed. Each sample was added with MTT solution (3-[4,5-dimethylthiazol-2-yl] 2,5-diphenyltetrazolium bromide; $0.5 \mathrm{mg} / \mathrm{ml}$ ), and was reacted in a $\mathrm{CO}_{2}$ culture incubator at $37^{\circ} \mathrm{C}$ for 2 hours. Insoluble crystals obtained in the process were completely melted with dimethylsulfoxide (DMSO), and their absorbance was measured at $570 \mathrm{~nm}$ using a microplate reader. The cytotoxicity of each sample was also examined.

\section{Measurement of inhibitory activity against collagenase}

For the reaction group, an $0.1 \mathrm{M}$ Tris-HCI buffer ( $\mathrm{pH} 7.5$ ) was added with $4 \mathrm{mM} \mathrm{CaCl}_{2}$, and $0.15 \mathrm{ml}$ of collagenase $(0.2 \mathrm{mg} / \mathrm{ml})$ was added to the mixed solution of $0.1 \mathrm{ml}$ of the sample solution and $0.25 \mathrm{ml}$ of the substrate (in which 4-phenylazobenzyl oxycarbonyl-Pro-Leu-Gly-Pro-Arg $(0.3 \mathrm{mg} / \mathrm{ml})$ was melted). After the mixed solution was reacted at room temperature for 20 minutes, $0.5 \mathrm{ml}$ of $6 \%$ citric acid was added to it to stop the reaction. After that, $1.5 \mathrm{ml}$ of 
ethylacetate was added to it, and the absorbance of the supernatant was measured at $320 \mathrm{~nm}$. Inhibitory activity against collagenase was expressed as the reduction rate of the measured absorbance of the control group not added with the prepared sample solution and the group added with the prepared sample solution.

\section{Measurement of inhibitory activity against elastase}

Inhibitory activity against porcine pancreas elastase was examined by measuring the amount of p-nitroanilide generated at $37^{\circ} \mathrm{C}$ for 30 minutes using $\mathrm{N}$-succinyl-(L-Ala)3-p-nitroanilide as a substrate. Each experimental solution was prepared to have a constant concentration, and $0.1 \mathrm{ml}$ was injected into a test tube. It was added with $0.05 \mathrm{ml}$ of the elastase, pancreatic solution (Type I: From Porcine Pancreas, 0.6 units $/ \mathrm{ml}$ ) melted in a $50 \mathrm{mM}$ Tris-HCl buffer (pH 8.6), and $0.1 \mathrm{ml}$ of $\mathrm{N}$-succinyl-(L-Ala)3-p-nitroanilide $(1 \mathrm{mg} / \mathrm{ml})$ melted in a 50mM Tris-HCl buffer $(\mathrm{pH} 8.6)$ as a substrate was added, and was reacted for 30 minutes. Its absorbance was measured at $410 \mathrm{~nm}$ using a microplate reader. Inhibitory activity against elastase was expressed as the reduction rate of the measured absorbance of the group not added with the prepared sample solution and the group added with the prepared sample solution).

\section{Measurement of inhibitory activity against tyrosinase}

In a test tube, $0.2 \mathrm{ml}$ of the substrate solution $(10 \mathrm{mM} \mathrm{L-DOPA} \mathrm{melted} \mathrm{in} 0.5 \mathrm{ml}$ of $1 / 15 \mathrm{M}$ sodium phosphate buffer (pH 6.8)) and $0.1 \mathrm{ml}$ of the sample solution were mixed together, and $0.2 \mathrm{ml}$ of 110 Unit/ml mushroom tyrosinase was added. After that, the mixed solution was reacted at $25^{\circ} \mathrm{C}$ for 2 minutes, and the absorbance of DOPA chrome generated in the reacted solution was measured at $475 \mathrm{~nm}$ using a microplate reader. Inhibitory activity against tyrosinase was expressed as the reduction rate of the measured absorbance of the group not added with the prepared sample solution and the groups added with the prepared sample solution.

\section{Assessment of collagen biosynthesis}

Cells $\left(2 \times 10^{6}\right.$ cells/well) were divided into a 6-well plate, and each well was added with Q3G7R at the concentration of $1 \mu \mathrm{g} / \mathrm{mL}$. Cells were cultured in a $\mathrm{CO}_{2}$ incubator for 24 hours, and the amount of propeptide was measured using a procollagen type-I C peptide (PIP) EIA kit (Takara), based on the method suggested in earlier studies, to test the biosynthesis of collagen within the cell culture fluid.

\section{Inhibitory activity against Matrix Metalloproteinase-1 (MMP-1)}

Cells ( $2 \times 10^{5}$ cells/well) were divided into a 6-well plate, and each well was added with Q3G7R at the concentration of $1 \mu \mathrm{g} / \mathrm{mL}$. Cells were cultured in a CO2 incubator for 24 hours, and the treated cell culture fluid was collected to test. Using the method suggested by Gross and Lapiere (1962) the absorbance of the collected cell culture fluid was measured using a Matrix Metalloproteinase-1 Biotrack activity Assay Kit (Amersham Bioscience) and a plate reader. The activity of MMP-1 within the cell culture fluid was quantified using an equation obtained through the standard curve.

\section{In-vivo UVB test and assessment of anti-photoaging effect}

A UV test was performed using the method suggested by Park et al. (2008). At a certain time everyday, $50 \mu \mathrm{L}$ of the coating solution was coated on the back of hairless mice, and UVB was irradiated after 30 minutes. The applied amount of UVB was determined by measuring the minimum erythema dose (MED). During the first week, $60 \mathrm{~mJ} / \mathrm{cm}^{2}$ equal to 1 
MED was applied to each mouse, and during the second to fourth weeks, $100 \mathrm{~mJ} / \mathrm{cm}^{2}$ equal to $2 \mathrm{MED}$ was irradiated for three weeks. UVB was irradiated using a UV irradiator that used UVB lamp GL20SE (Sankyo denki, Japan), and the amount of UV irradiation was measured using Solarmeter (Solartech Inc., Harrison Township, MI, USA) to control the time of exposure. Changes in the thickness of the skin were measured by folding the skin using Digimatic Micrometer (Mitsutoyo Co., Tokyo, Japan).

\section{Tissue staining}

The skin was removed from the back of hairless mice was co, and was fixed in a $10 \%$ formalin solution for a day. The collected tissues were stained using the H\&E staining method.

\section{Statistical analysis}

Analysis was repeated three times, and the results of analysis were expressed as mean $\pm \mathrm{SD}$. The significance of the results was tested using Student's t-test, and when the confidence level is 5\% $(p<.05)$, the results are considered to be statistically significant.

\section{Results and Discussion}

\section{Measurement of electron donating (DPPH) activity}

Studies on skin wrinkles show that oxygen free radicals caused by UV or stress, and those generated within the body accelerate the activity of collagenases such as MMPs (Matrix metalloproteinase), and inhibit the synthesis of collagen, which reduces the elasticity of the skin and accelerates the generation of wrinkles. In line with that, the antioxidant effect of the extract of collagen-coated coffee beans was measured using the DPPH method. Differences in the DPPH radical scavenging activity between the control group that used coffee beans not coated with collagen and the treated groups that used coffee beans coated with collagen were compared. The antioxidant effect of Collafee bean presso that contained more collagen was higher than that of the coffee extract used in the control group, but there was no statistically significant difference (Figure 1).

\section{Measurement of inhibitory activity against collagenase}

The inhibitory activity of the extract from collagen-coated coffee beans against collagenase was measured, and the

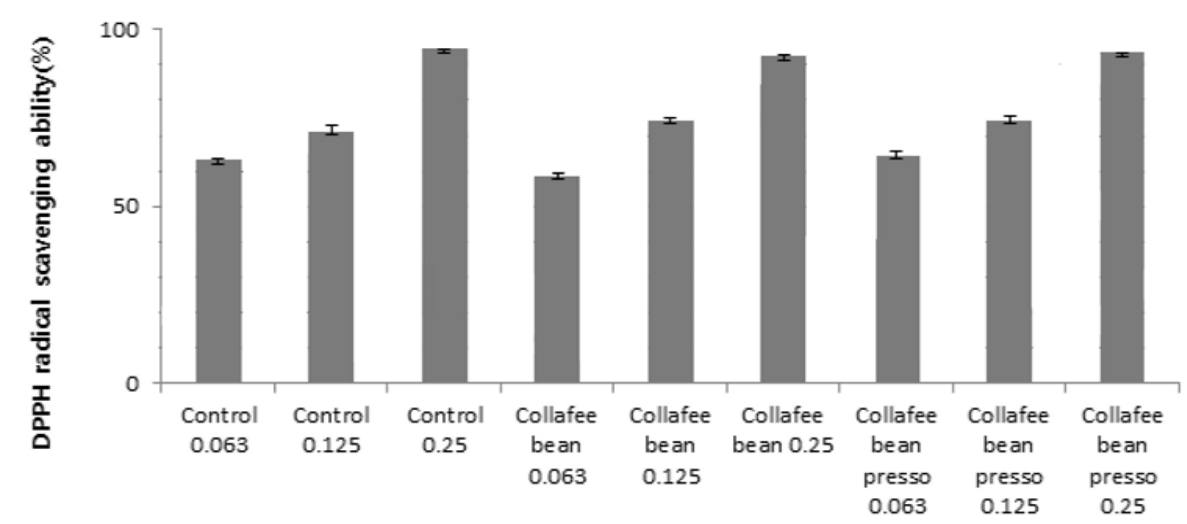

Figure 1. Effect of Collafee bean extracts on DPPH radical scavenging activities. 
inhibitory activity was measured to be almost $100 \%$ at a concentration of $25 \mathrm{mg} / \mathrm{ml}$. The inhibitory activity of collagencoated coffee beans against collagenase was similar to that of coffee beans that were not coated with collagen in the control group, showing no statistically significant difference in inhibitory activity against collagenase depending on the treatment of collagen coating (Figure 2).

\section{Measurement of inhibitory activity against elastase}

The inhibitory activity of the extract from collagen-coated coffee beans against elastase was measured, and the inhibitory activity of the extract at a concentration of $3.13 \mathrm{mg} / \mathrm{ml}$ was $30 \%$ and $34 \%$, and that of the extract at a concentration of $12.5 \mathrm{mg} / \mathrm{ml}$ was $56.6 \%$ and $57.4 \%$, demonstrating the effect of inhibiting elastase. Similar to inhibitory activity against collagenase, the inhibitory activity of collagen-coated coffee beans against elastase was similar to that of coffee beans that were not coated with collagen in the control group, showing no difference in inhibitory activity against elastase depending on the existence of collagen coating (Figure 3).

\section{Measurement of inhibitory activity against tyrosinase}

The inhibitory activity of the extract from collagen-coated coffee beans against tyrosinase was measured. The IC50

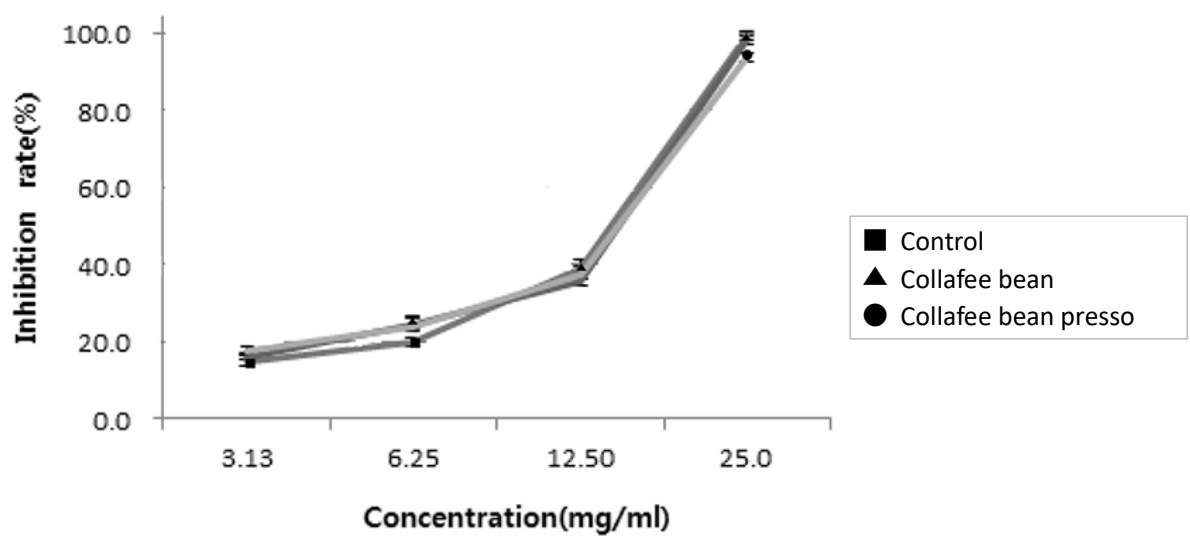

Figure 2. Inhibitory effects of Collafee bean extracts on collagenase activities.

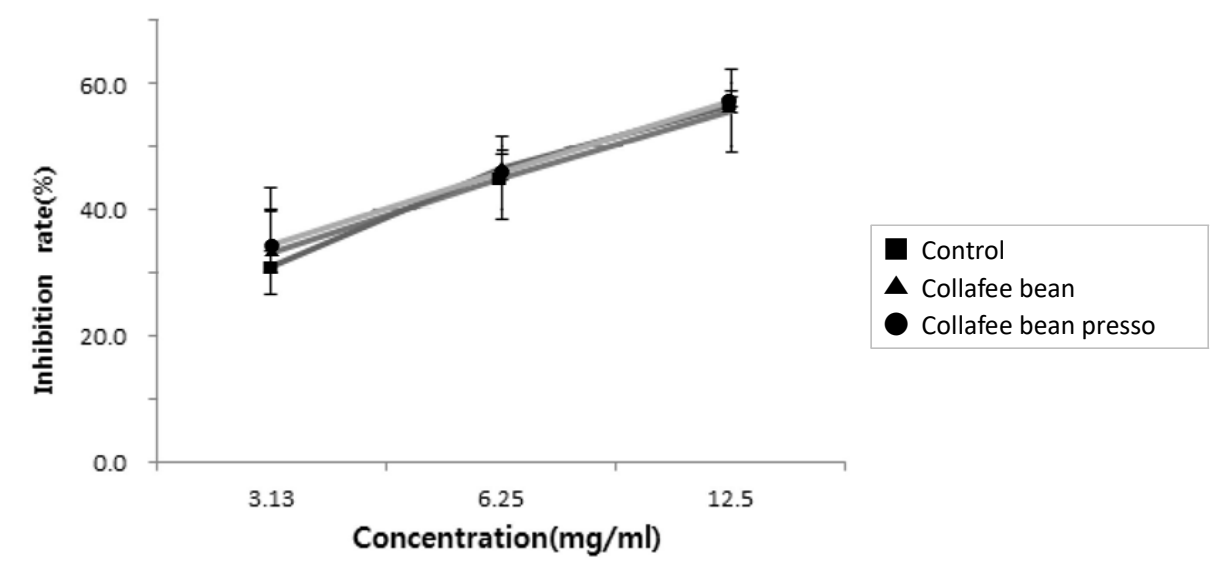

Figure 3. Inhibitory effects of Collafee bean extracts against elastase activities. Results are expressed as mean \pm SD of data obtained from three independent experiments. 
value that shows the inhibitory effect of $50 \%$ was compared, and the following results were obtained: Collafee bean $\gg$ Collafee bean presso > non-coated. That is, the inhibitory effect of coffee beans coated with low-concentration collagen against tyrosinase was higher, but there was no statistically significant difference (Figure 4).

When the skin is exposed to UV light, melanin generated by a series of oxidative polymerization reactions, starting from tyrosine, causes pigmentation and accelerates skin aging. Melanin in the skin is a protein complex generated in melanocytes that exist in the stratum basale, and the synthesis of melanin is controlled by tyrosinase. Meanwhile, the extract of mulberry roots is used to produce functional cosmetic products for skin whitening, and is known to have $92 \%$ of the tyrosinase-inhibiting effect at a concentration of $50 \mu \mathrm{g} / \mathrm{mL}$ (Ryu, 2011). Compared to this, the inhibitory effect of coffee does not seem to have a whitening function.

\section{Measurement of cell viability}

To examine the impact of the extract of collagen-coated coffee beans on the survival of cells, the extract at a concentration of $0.3125,0.625,1.25,2.5$ and $5 \mathrm{mg} / \mathrm{ml}$ was added to culture media individually, and, after that, the viability of cells was measured using a MTT assay. The cytotoxicity of the coffee extract against CCD-986sk, human dermal fibroblast (HDF) cells, is as shown in Figure 5. The cell viability of the control, Collafee bean, and Collafee bean presso

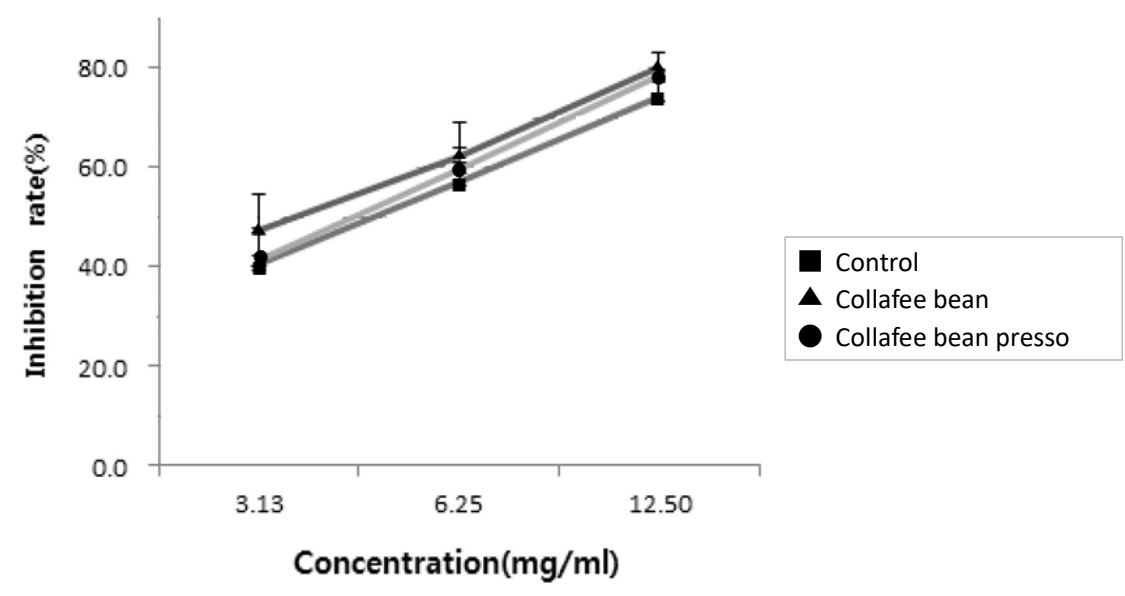

Figure 4. Inhibitory effects of Collafee bean extracts against tyrosinase activities. Results are expressed as mean \pm SD of data obtained from three independent experiments.

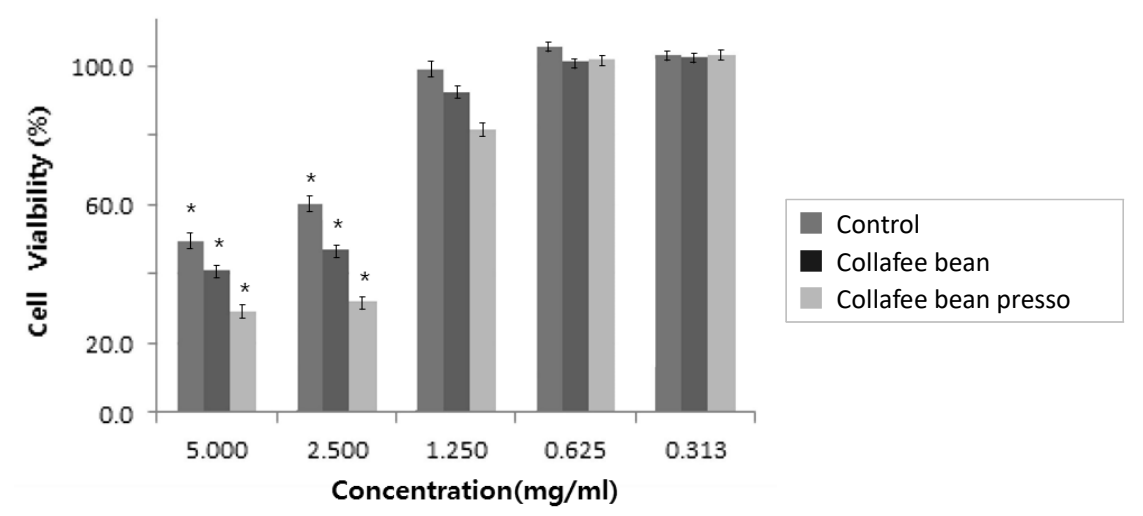

Figure 5. Cell viability of Collafee bean extracts on fibroblast cell(CCD-986sk). Results were expressed as \% of control and data were means \pm SD. Significant differences were compared with control. ${ }^{*} p<.05$. 
groups at a concentration of $1.25 \mathrm{mg} / \mathrm{ml}$ was $99.2 \%, 92.5 \%$ and $82.0 \%$ respectively, and at a concentration of $0.625 \mathrm{mg} / \mathrm{ml}$, $100 \%$. All the treated groups showed dose-dependent cell death rates. In particular, compared to the coffee beans used in the control group, as the amount of collagen coated on coffee beans in the treated groups increased, the cell death rate tended to increase, but the difference does not seem to be significant compared to the results of other herb medicine-treated groups suggested in earlier studies. The level of cytotoxicity is no cause for concern.

\section{Assessment of collagen biosynthesis}

Fibroblast cells are cells that biosynthesize collagen fibers, elastin fibers and mucopolysaccharide that are constituents of the dermis. When the activity of fibroblasts is reduced by various causes such as aging and UV light, collagen fibers, elastin fibers and mucopolysaccharides are not sufficiently supplied to the skin, which shrinks dermis tissues, reduces elasticity and thus creates wrinkles. To assess the synthesis of collagen in fibroblasts (CCD-986sk) depending on the treatment of coating, fibroblast cells were treated with the extract of coffee beans and changes in the generated amount of collagen were measured by measuring procollagen type-I C peptide (PIP) using an EIA kit. The results are as shown in Figure 6.

When the cells were treated with retinoic acid at a concentration of $0.05 \mu \mathrm{g} / \mathrm{ml}, 233.6 \mathrm{ng} / \mathrm{ml}$ of collagen was generated. When they were treated with the coffee extract at a concentration of $312.5 \mu \mathrm{g} / \mathrm{ml}$, the amount of collagen generated in the control, Collafee bean and Collafee bean presso groups was $190.6 \mathrm{ng} / \mathrm{ml}, 187.7 \mathrm{ng} / \mathrm{ml}$ and $195.2 \mathrm{ng} / \mathrm{ml}$ respectively. The Collafee bean presso group showed an increase by $2.8 \%$, compared to the normal group, which demonstrates that the collagen-coated coffee bean samples increased the amount of collagen.

\section{Inhibitory activity against Matrix Metalloproteinase-1 (MMP-1)}

The cytotoxicity test was performed to measure the inhibitory activity of samples against MMP-1, and the viability of the control, Collafee bean and Collafee bean groups at a concentration of $82.5 \mu \mathrm{g} / \mathrm{ml}$ was $91.2 \%, 98.4 \%$ and $86.6 \%$ respectively, and at a concentration of $14.3 \mu \mathrm{g} / \mathrm{ml}, 100 \%$. For this reason, the concentration level was set between $82.5 \mu \mathrm{g} / \mathrm{ml}$ and $14.3 \mu \mathrm{g} / \mathrm{ml}$ in the MMP-1 inhibitory activity test (Figure 7).

Connective tissues in the dermis are mainly composed of collagen and elastin, and the dermis has fibroblasts that synthesize and produce collagen and elastin. Collagen and elastin give elasticity to and support the skin, and when they become weak due to aging, the skin is easily damaged and aged. In addition, repeated exposure to UV light create

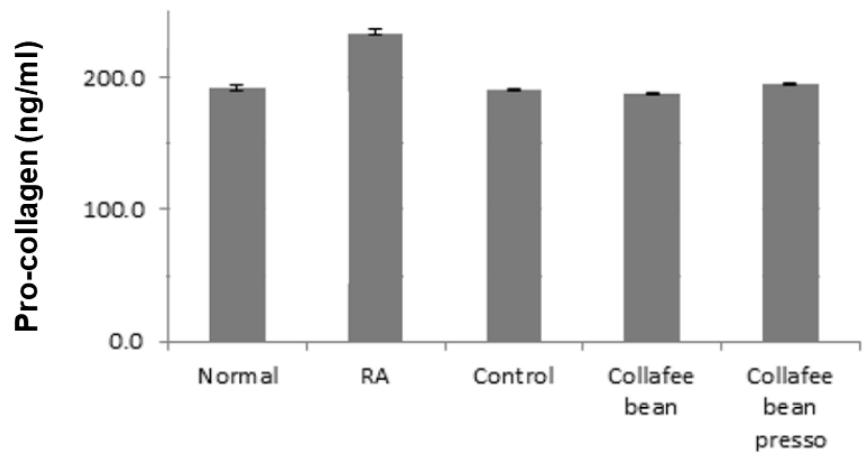

Figure 6. Procollagen synthesis of Collafee bean extracts on fibrolast cell (CCD-986sk). Results are expressed as mean \pm SD of data obtained from three independent experiments. RA=Retinoic acid. 
cytokines that inhibit the synthesis of collagen in the skin and increase the expression of enzymes that degrade collagen. In particular, matrix metalloproteinases (MMPs), a collagenase in the skin, increases, which repeatedly degrades collagen in the skin, and thus causes wrinkles. Therefore, to reduce wrinkles, it is necessary to inhibit the expression and activity of MMPs, and thus the degradation of connective tissues, and to increase the activity of fibroblasts in order to supply new connective tissues.

CCD-986sk cells were treated with UVB and TNF- $\alpha$ ( $1 \mathrm{ng} / \mathrm{ml})$, and the activity of MMP-1 was measured as shown in Figure 8. The activity of MMP-1 in the control, Collafee bean, and Collafee bean presso groups at a coffee extract concentration of $78.25 \mu \mathrm{g} / \mathrm{ml}$ was reduced by $13 \%, 11 \%$ and $10 \%$ respectively, compared to the control group not treated with the sample solution after the treatment of UVB and TNF- $\alpha(1 \mathrm{ng} / \mathrm{ml})$ (Figure 8).

\section{Assessment of In-vivo anti-photoaging effect}

When the skin is exposed to UV light, changes in the physical and biochemical properties of skin tissues are caused. UV irradiation increases the horny and epidermal layers, and, in this study, the groups treated with the extract of collagencoated coffee beans showed a dose-dependent decrease in the thickness of the skin, compared to the control group treated

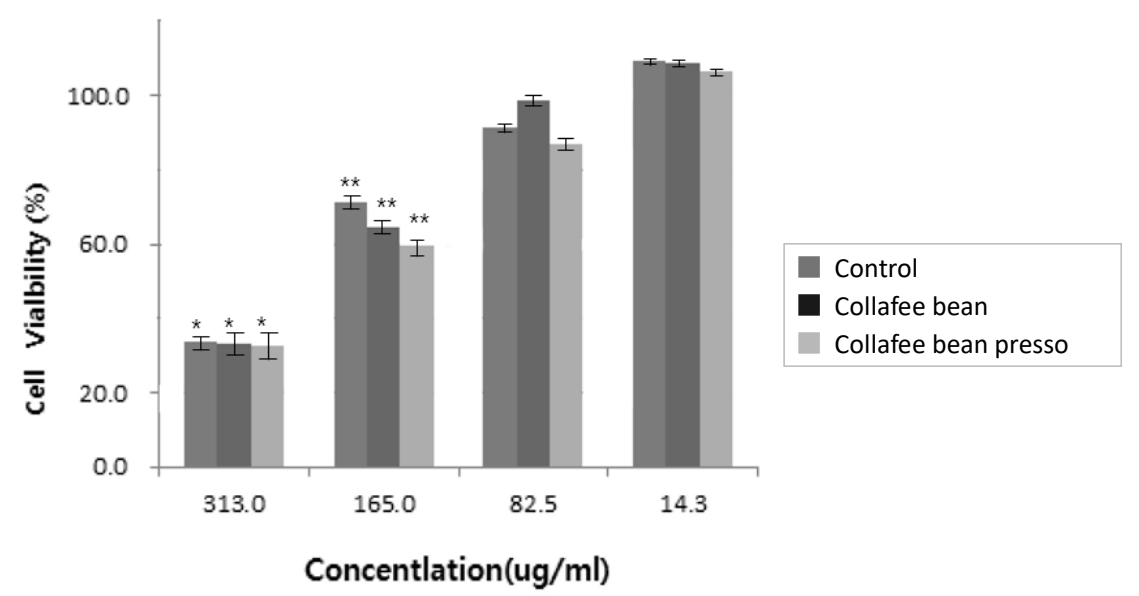

Figure 7. Cell viability of Collafee bean extracts on fibroblast cell(CCD-986sk). Results were expressed as \% of control and data were means \pm SD. Significant differences were compared with control. ${ }^{*} p<.05,{ }^{* *} p<.01$.

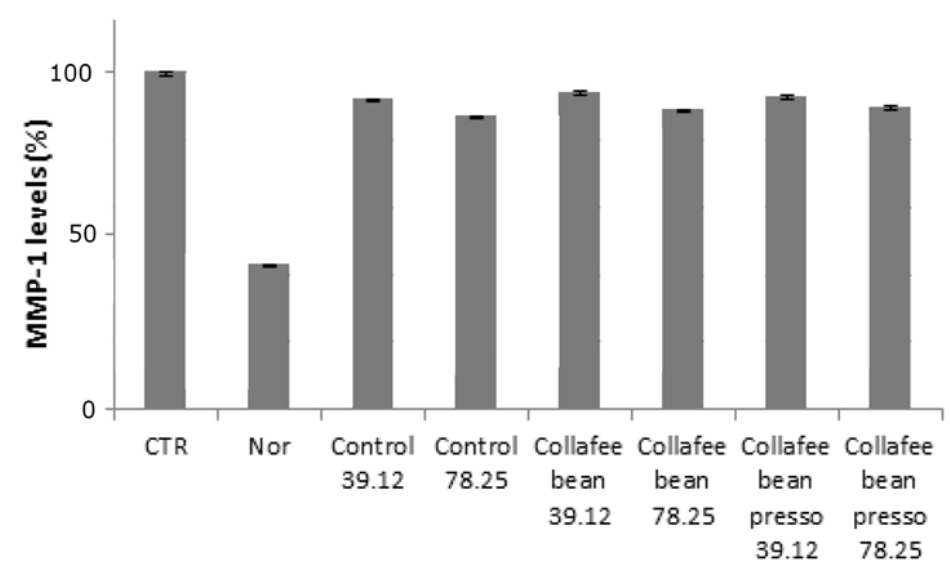

Figure 8. MMP-1 activities of Collafee bean extracts on fibrolast cell (CCD-986sk). Results are expressed as mean \pm SD of data obtained from three independent experiments. 
with the coffee extract (Table 1).

In addition, long-term exposure to UV light in general increases the thickness of the epidermal layer over 2 3 times, and pleomorphic horny cells are observed in the epidermal layer. In the dermal layer, the deformed fiber structures of collagen and elastin are observed. That is, the thickness of the skin is increased as photoaging caused by UV light, unlike natural aging, increases the thickness of the horny layer to protect the dermal layer. The results of the H\&E staining test showed that the thickness of the epidermal layer increased in the control group, while the thickness of the horny layer in the groups that used collagen-coated coffee beans was reduced (Figure 9).

UVB irradiation accelerates the creation of Nitricoxide (NO) and inflammatory factors such as prostaglandin E2, and excessively generates ROS, which destroys cell membranes and aggravates skin damage (López-Camarillo et al., 2012). It also accelerates the creation of pro-inflammatory cytokines such as IL-1 $\beta$ and IL-6, causing inflammatory reactions (Hiromi et al., 2011). IL-1 is involved in the activity of paracrine and the excessive degradation of collagen, and plays a key role in the photoaging of the skin (Wang and $\mathrm{Bi}, 2006$ ). It increases the activity of mastocytes upon UVB irradiation, and causes the generation and discharge of factors like histamine and IL-6, which results in inflammation and pain as well as itchiness, and thus further aggravate damage to the horny layer (Böhm et al., 2006). In addition, UV irradiation to the skin activates collagenases within the skin, which degrades collagen that contributes to the elasticity of the skin, and accelerates the dryness and aging of the skin (Imokawa et al., 2015). As these studies show, excessive oxidative stress generated by continuous exposure to UV light cuts the chains of collagen, elastin and hyaluronic acid and accelerates the creation of melanin, which reduces skin elasticity and causes skin aging along with wrinkles and pigmentation (Ha et al., 2015; Xuan et al., 2016). The increasing activity of keratinocytes caused by UVB irradiation induces the creation of cytokines, and activates fibroblasts, generating cytokines and the expression of MMP-1 proteins (Kim et al., 2018).

Table 1. Inhibitory effect of Collafee bean extracts on UVB-irradiated mouse skin

\begin{tabular}{lcc}
\hline Group & Skin thickness $(\mathrm{mm})$ & Inhibition $(\%)$ \\
\hline Normal & $0.41 \pm 0.02$ & - \\
Negative control & $0.98 \pm 0.05$ & $5.5 \pm 8.5$ \\
Control & $0.95 \pm 0.07$ & $11.8 \pm 7.8$ \\
Collafee bean & $0.87 \pm 0.05^{*}$ & $21.3 \pm 6.6$ \\
Collafee bean presso & $0.83 \pm 0.04^{* *}$ & \\
\hline
\end{tabular}

Note. Mean $\pm \mathrm{SD}(\mathrm{n}=5)$. Percent of control values.

${ }^{*} p<.05,{ }^{* *} p<.01$ when compared with negative control group.

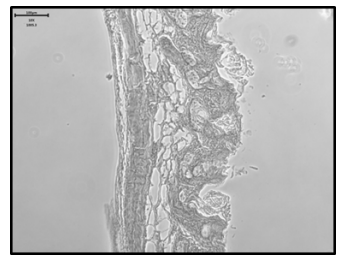

Normal

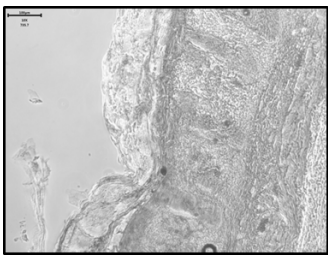

CTR

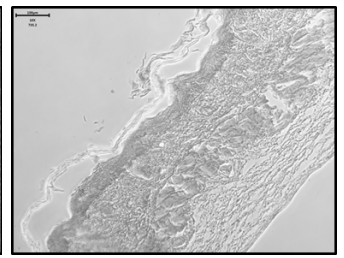

Control 100

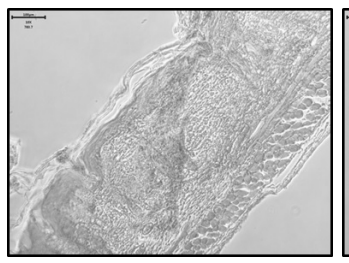

Collafee bean 100

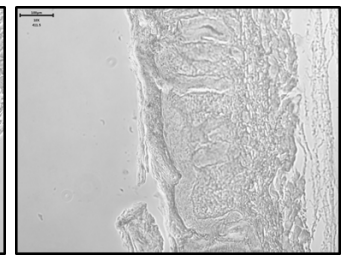

Collafee bean presso 100

Figure 9. Microscopic evaluation of effect of Collafee bean extracts on UVB-damaged skin in hairless mouse. Skin section ( $5 \mathrm{~mm}$ ) was prepared and stained using H\&E staining method. Normal=UV not treated; CTR=Negative control; Control $100=100 \mu$ l of coffee treated; Collaffee bean $100=100 \mu$ of low dose collagen coated coffee treated; Collaffee bean presso $100=100 \mu$ l of high dose collagen coated coffee treated. 
As the skin ages, the density of fibroblasts decreases and shows a significant correlation with the density of collagen fibers and elastic fibers, reducing the number of fibroblasts. The decreasing density of collagen fibers and elastic fibers decreases indicates the involvement of fibroblasts in the performance of protein synthesis (Song et al., 2007).

Collagen slows down the generation of wrinkles and a decrease in skin elasticity caused by UV light and restores the damaged dermal layer (Kim et al., 2011), and the intake of collagen increases the thickness of the dermal layer and eases pigmentation (Jeon and Kang, 2009). It was also reported that the intake of collagen peptides protects skin barriers (Kim et al., 2011). Collagen is an important constituent that forms the skeletal system of vertebrate and invertebrate animals, and, in particular, collagen is an important fiber protein that composes mammals' skin, cartilage, tissue and tendon (Pei et al., 2000), but the synthesis of collagen decreases and matrix metallo proteinases (MMPs) that degrade collagen increases with age (Banning, 2008). Therefore, it seems to be easier to increase the concentration of collagen in the blood with the antecedents of collagen absorbed as a peptide through the intake of collagen than to induce the synthesis of collagen with amino acid digested and absorbed from proteins (Kang and Lee, 2010), which has increased interest in collagen peptides. In particular, the absorption rate of collagen is important, and it was reported that administering collagen with vinegar increases the absorption of collagen (Kang and Lee, 2010).

The oral intake of collagen is also known to strengthen and shine hair and finger and toe nails. Kim et al. (2009) observed the protecting effect of collagen peptide compounds against skin damage such as the loss of skin moisture induced through the in-vivo UV treatment for 10 weeks, and reported that the intake of the compounds eased symptoms caused by the UV treatment such as the increasing number of wrinkles, the reduced elasticity of the skin, the increasing proliferation of abnormal horny cells and thus the increasing thickness of the skin, and that collagen peptide compounds protect the skin from UV, improve the elasticity and moisturizing ability of the skin, and thus contributes to the normal functioning of the skin (Kim et al., 2009). It was also reported that collagen peptides increased the diameter and density of dermal collagen fibers in vivo, and that the oral intake of collagen peptides improved the skin in an in-vivo photoaging model (Shigemura et al., 2009; Kikuta et al. 2003; Sibilla et al., 2015). Preclinical studies that used animal models reported that collagen peptides or gelatin thickened collagen fibers (Matsuda et al., 2006; Minaguchi et al., 2005). The intake of collagen peptides was also found to have the effect of healing ulcers similar to the intake of arginine (Nakao et al., 2013), and the repeated oral administration of hydroxy proline and Pro-Hyp significantly moisturized the skin photoaged by UV light, reduced the thickness of the skin, and restored the damaged dermal layer (Lee et al., 2008). In addition, low molecular asteriasamurensis collagen peptides were reported to block signaling pathways that increase the activity of AP-1 under UVA irradiation, and to inhibit the expression of MMP-1, contributing to reducing wrinkles (Kwon et al., 2007).

Commercialized collagen peptides are made by extracting and heating high molecular collagen from fish scales and the skin of pigs and cows to transform it into gelatin and hydrolyzing gelatine. The collagen peptides are degraded by enzymes into amino acid in the body, but collagen peptides are resynthesized by vitamin (Shin et al., 2016). Among various collagen peptides, fish scale collagen can be easily cleaned and dried (Jung et al., 2015), and thus it is necessary to develop materials by utilizing collagen peptides extracted from fish scales. Against this backdrop, this study compared the effect of coffee beans coated with fish scale collagen peptides on skin aging.

Photo or intrinsic aging reduces collagen fibers in the dermal layer, creates wrinkles on the skin and makes the skin sag and loose elasticity. In addition, elastin proteins that have mesh structures in the dermal layer are also reduced, which is known to be closely related to the reduced elasticity of the skin. Therefore, the long-term oral intake of collagen peptide compounds that contain a small amount of elastin peptides significantly increases the synthesis of procollagen in fibroblasts in the dermal layer, which is expected to ease the generation of wrinkles and the reduced elasticity of the skin caused by the damaged dermal layer structure by UV. 


\section{Conclusion}

The effects of the extract of coffee beans (Coffea arabica, C. canephora) of the Rubiaceae family, and those coated with collagen peptides on skin aging, specifically photoaging, were examined based on several criteria including improvement in wrinkles, whitening, antioxidation, and collagen synthesis in fibroblasts. Fish collagen peptide powder separated from fish scales (1.3\%) was coated on coffee beans, and the extract of the coated coffee beans was used in the tests of enzyme inhibition and animals. There was no significant effect of collagen on inhibiting the activity of enzymes associated with skin aging, pigmentation, reducing wrinkles and antioxidation. However, the long-term oral intake of collagen peptide compounds with coffee was found to significantly increase the synthesis of procollagen in fibroblasts in the dermal layer and to ease the thickened horny layer and skin caused by UV light. Based on these results, it is expected to contribute to ease the generation of wrinkles and the reduced elasticity of the skin caused by the damaged structure of the skin from a long-term perspective. Collagen-coated coffee showed a dose-dependent increase in the biosynthesis of collagen, and thus the oral intake of collagen-coated coffee is expected to ease the thickened horny layer caused by photoaging and the reduced density of fibroblasts caused by aging. Therefore, coating coffee beans with collagen peptides (1.3 wt $\%)$ can be utilized in developing functional beverages.

\section{References}

Banning, M. 2008. Ageing and the gut. Nurs. Older People 20(1):17-21.

Benzie, I.F. 2000. Evolution of antioxidant defense mechanisms. Eur. J. Nutr. 39(2):53-61.

Bicchi, C.P., A.E. Binello, G.M. Pellegrino, and A.C. Vanni. 1995. Characterization of green and roasted coffees through the chlorogenic acid fraction by HPLC-UV and principal component analysis. J. Agric. Food Chem. 43(6):1549-1555. DOI:10.1021/jf00054a025

Bidel, S. and J. Tuomilehto. 2012. The emerging health benefits of coffee with an emphasis on type 2 diabetes and cardiovascular disease. Eur. Endocrinol. 9(2):99-106. DOI:10.17925/EE.2013.09.02.99

Böhm, M., T.A. Luger, D.J. Tobin, and J.C. García-Borrón. 2006. Melanocortin receptor ligands: New horizons for skin biology and clinical dermatology. J. Investig. Dermatol. 126(9):1966-1975. DOI:10.1038/sj.jid.5700421

Choi, Y.H., S.E. Kim, J. Huh, Y.H. Han, and M.J. Lee. 2012. Antibacterial and antioxidative activity of roasted coffee and red ginseng mixture extracts. J. Korean Soc. Food Sci. Nutr. 41(3):320-326. DOI:10.3746/jkfn.2012.41.3.320

Delgado-Andrade, C. and F.J. Morales. 2005. Unraveling the contribution of melanoidins to the antioxidant activity of coffee brews. J. Agric. Food Chem. 53(5):1403-1407. DOI:10.1021/jf048500p

Gross, J. and C.M. Lapiere. 1962. Collagenolytic activity in amphibian tissues: A tissue culture assay. Proc. Natl. Acad. Sci. U S A. 48(6):1014-1022.

Ha, J.H., Y.J. Jeong, J.S. Seong, K.M. Kim, A.Y. Kim, M.M. Fu, J.Y. Shu, N.H. Lee, J.O. Park, and S.N. Park. 2015. Antioxidant and antibacterial activities of Glycyrrhiza uralensis fisher (Jecheon, Korea) extracts obtained by various extract conditions. J. Soc. Cosmet. Sci. Korea. 41(4):361-373. DOI:10.15230/SCSK.2015.41.4.361

Hiromi, N., H. Nakano, Y. Matsuzaki, D. Sawamura, and K. Hanada. 2011. Immunohistochemical analysis of in vivo UVB-induced secretion of IL-1 $\alpha$ and IL-6 in keratinocytes. Mol. Med. Rep. 4(4):611-614. DOI:10.3892/mmr.2011.478

Hong, K.O. 2018. Analysis on the trends of coffee related research in Korea and future research direction. J. Tour. Leis. Res. 30(2):421-437. Retrieved from http://www.kastle.kr

Imokawa, G., H. Nakajima, and K. Ishida. 2015. Biological mechanisms underlying the ultraviolet radiation-induced formation of skin wrinkling and sagging II: over-expression of neprilysin plays an essential role. Int. J. Mol. Sci. 16(4): 7776-7795. DOI:10.3390/ijms16047776

Jeon, Y.S. and S.M. Kang. 2009. Influence of collagen intake upon facial-skin dermis and pigmentation. J. Korean Soc. Cosmetol. 15(3):745-756. 
Jung, Y.M., E.J. Bang, and S.T. Kang. 2015. Quality characteristics of noodles added with freeze-dried fish scale collagen mixture powder. J. Korean Soc. Food Sci. Nutr. 44(3):449-454. DOI:10.3746/jkfn.2015.44.3.449

Kang, S.M. and H.N. Lee. 2010. The Effect of imbibing collagen and vinegar simultaneously on the serum of climacteric women. J. Korean Soc. Cosmetol. 16(4):1051-1064.

Kikuta, T., Y. Sakai, Y. Tsuda, and H. Kojima. 2003. The development of highly functional collagen tripeptide. Fragr. J. 31(1):61-67.

Kim, H.L., S.M. Woo, W.R. Choi, H.S. Kim, C. Yi, K.H. Kim, J. Cheng, S.H. Yang, and J.W. Suh. 2018. Scopoletin downregulates MMP-1 expression in human fibroblasts via inhibition of p38 phosphorylation. Int. J. Mol. Med. 42(4): 2285-2293. DOI:10.3892/ijmm.2018.3757

Kim, I.H., J.K. Kim, and J.H. Lee. 2016. Antimicrobial and antioxidant effects of functional healthy drinks from some medicinal herbs and coffee mixture. J. Life Sci. 26(11):1225-1231. DOI:10.5352/JLS.2016.26.11.1225

Kim, J.K., J.H. Lee, I.H. Bae, D.B. Seo, and S.J. Lee. 2011. Beneficial effect of a collagen peptide supplement on the epidermal skin barrier. Korean J. Food Sci. Technol. 43(4):458-463.

Kim, J.K., J.H. Lee, M.S. Yang, D.B. Seo, and S.J. Lee. 2009. Beneficial effect of collagen peptide supplement on anti-aging against photodamage. Korean J. Food Sci. Technol. 41(4):441-445.

Kwak, H.S., Y.H. Jeong, and M.S. Kim. 2018. Effect of yeast fermentation of green coffee beans on antioxidant activity and consumer acceptability. J. Food Qual. 2018(Article ID 5967130):1-8. DOI:10.1155/2018/5967130

Kwon, M.C., C.H. Kim, H.S. Kim, A.Q. Syed, B.Y. Hwang, and H.Y. Lee. 2007. Anti-wrinkle activity of low molecular weight peptides derived from the collagen isolated from Asterias amurensis. Korean J. Food Sci. Technol. 39(6):625-629.

Lee, J.H., J.H. Seo, Y.H. Park, W.G. Kim, K.M. Lim, and S.J. Lee. 2008. The effect of hydroxyproline and Pro-Hyp dipeptide on UV-damaged skin of hairless mice. Korean J. Food Sci. Technol. 40(4):436-442.

Lee, M.K., H.J. Kim, and M.K. Park. 2018. Regulation effects of orofacial pain by green coffee bean extracts in rats. J. Korean Soc. Oral Health Sci. 6(2):53-58.

Lim, Y.R., J.Y. Shin, H. Kim, G.H. Baek, K.W. Yu, H.S. Jeong, and J.S. Lee. 2014. Anti-adipogenic effect of fermented coffee with Monascus ruber Mycelium by solid-state culture of green coffee beans. J. Korean Soc. Food Sci. Nutr. 43(4):624-629. DOI:10.3746/jkfn.2014.43.4.624

López-Camarillo, C., E.A. Ocampo, M.L. Casamichana, C. Pérez-Plasencia, E. Álvarez-Sánchez, and L.A. Marchat. 2012. Protein kinases and transcription factors activation in response to UV-radiation of skin: Implications for carcinogenesis. Int. J. Mol. Sci. 13(1):142-172. DOI:10.3390/ijms 13010142

Matsuda, N., Y. Koyama, Y. Hosaka, H. Ueda, T. Watanabe, T. Araya, S. Irie, amd K. Takehana. 2006. Effects of ingestion of collagen peptide on collagen fibrils and glycosaminoglycans in the dermis. J. Nutr. Sci. Vitaminol. 52(3):211-215. DOI:10.3177/jnsv.52.211

Meng, S., J. Cao, Q. Feng, J. Peng, and Y. Hu. 2013. Roles of chlorogenic acid on regulating glucose and lipids metabolism: A review. Evid. Based Complement. Alternat. Med. 2013(Article ID 801457):1-11. DOI:10.1155/2013/801457

Minaguchi, J., Y. Koyama, N. Meguri, Y. Hosaka, H. Ueda, M. Kusubata, A. Hirota, S. Irie, N. Mafune, and K. Takehana. 2005. Effects of ingestion of collagen peptide on collagen fibrils and glycosaminoglycans in Achilles tendon. J. Nutr. Sci. Vitaminol. 51(3):169-174.

Moreira, D.P., M.C. Monteiro, M. Ribeiro-Alves, C.M. Donangelo, and L.C. Trugo. 2005. Contribution of chlorogenic acids to the iron-reducing activity of coffee beverages. J. Agric. Food Chem. 53(5):1399-1402.

DOI:10.1021/jf0485436

Nakao, K., M. Kusubata, K. Hara, M. Igarashi, N. Yamazaki, and Y. Koyama. 2013. Effects of collagen peptide ingestion on healing of skin wound in a rat model of pressure ulcer. Japanese Pharmacol. Ther. 41(6):587-596.

Park, S.H., Y.M. Hong, Y,J. Choi, J.H. Choi, and B.K. Kim. 2008. Antiwrinkle effects of mugwort (Artemisia vulgaris) extracts on UVB-irradiated hairless mouse skin. J. Korean Soc. Food Sci. Nutr. 37(9):1136-1141. DOI:10.3746/jkfn.2008.37.9.1136

Pei, M., C. Yu, and M. Qu. 2000. Expression of collagen type I, II and III in loose body of osteoarthritis. J. Orthop. Sci. 5(3):288-293. DOI:10.1007/s007760050165 
Ryu, M.J. 2011. Inhibitory effect of Morus alba extracts on tyrosinase activity and melanogenesis in SK-MEL-2 cells. Korean J. Aesthet. Cosmetol. 9(4):1-12.

Santos, R.M.M. and D.R.A. Lima. 2016. Coffee consumption, obesity and type 2 diabetes: A mini-review. Eur. J. Nutr. 55(4):1345-1358. DOI:10.1007/s00394-016-1206-0

Shigemura, Y., K. Iwai, F. Morimatsu, T. Iwamoto, T. Mori, C. Oda, T. Taira, E.Y. Park, Y. Nakamura, and K. Sato. 2009. Effect of prolyl-hydroxyproline (Pro-Hyp), a food-derived collagen peptide in human blood, on growth of fibroblasts from mouse skin. J. Agric. Food Chem. 57(2):444-449. DOI:10.1021/jf802785h

Shin, H.J., J.I. Park, C.J. Kwon, H.Y. Kim, N. Inoue, S. Koizumi, and J.S. Hwang. 2016. The effect of collagen peptide intake on UVB-induced skin damage in hairless mice. J. Korea Acad. Ind. Coop. Soc. 17(3):611-621. DOI:10.5762/KAIS.2016.17.3.611

Shin, J.Y., H. Kim, D.G. Kim, G.H. Baek, H.S. Jeong, and K.W. Yu. 2013. Pharmacological activities of coffee roasted from fermented green coffee beans with fungal mycelia in solid-state culture. J. Korean Soc. Food Sci. Nutr. 42(3): 487-496. DOI:10.3746/jkfn.2013.42.3.487

Sibilla, S., M. Godfrey, S. Brewer, A. Budh-Raja, and L. Genovese. 2015. An overview of the beneficial effects of hydrolysed collagen as a nutraceutical on skin properties: Scientific background and clinical studies. Open Nutraceuticals J. 8:29-42. DOI:10.2174/1876396001508010029

Song, I.Y., M.A. Jeong, and J.H. Lee. 2007. A quantitative comparison of fibroblasts, collagen and elastic fiber densities in the young and aged rat skin. J. Exp. Biomed. Sci. 13(1):55-60.

Vignoli, J.A., D.G. Bassoli, and M.T. Benassi. 2011. Antioxidant activity, polyphenols, caffeine and melanoidins in soluble coffee: the influence of processing conditions and raw material. Food Chem. 124(3):863-868.

DOI:10.1016/j.foodchem.2010.07.008

Wang, X.Y. and Z.G. Bi. 2006. UVB-irradiated human keratinocytes and interleukin-1alpha indirectly increase MAP kinase/AP-1 activation and MMP-1 production in UVA-irradiated dermal fibroblasts. Chinese Med. J. 119(10):827-831.

Xuan, S.H., G.Y. Kim, J.Y. Yu, J.W. Kim, Y.R. Yang, Y.H. Jeon, Y.J. Jeong, A.R. Kim, and S.N. Park. 2016. Antioxidant and cellular protective effects against oxidative stress of Calendula officinalis flowers extracts in human skin cells. Appl. Chem. Eng. 27(6):620-626. DOI:10.14478/ace.2016.1093 